\title{
Disaster Preparedness Kit: An Insight into the Emergency Tool
}

\author{
Varghese A*, Swabir SF and George G \\ Department of Health Research, Bhopal memorial \\ Hospital and Research Centre, Government of India, \\ India \\ *Correspondling author: Varghese A, Bhopal \\ Memorial hospital And Research Centre, Department of \\ Health Research, Ministry of Health And Family Welfare \\ Government of India, Bhopal, Madhya Pradesh, India
}

Received: J une 29, 2017; Accepted: July 24, 2017;

Published: July 31, 2017

\begin{abstract}
Disaster and the aftermath of it are terrible. The humankind has experienced a number of traumatic disasters over the past few decades. As disasters cannot be prevented, contingency planning for disaster management involving preparedness, mitigation, relief and rehabilitation are essential. Even though disaster demands immediate response, the resilience after disaster depends upon the level of preparedness. The current study addresses Disaster Kit which is one of the most important priority tools in disaster preparedness. The Global initiatives for disaster preparedness and reduction should be given highest priority by the international community. The purpose of the article is to disseminate information related to disaster preparedness kit to the entire scientific community thereby empowering the concept of disaster preparedness to enable each individual and family to remain comfortable during and after disaster.
\end{abstract}

Keywords: Disaster; Disaster preparedness; Disaster Kit

\section{Introduction}

Disasters in modern times have transcended borders of nation, class and have devastating impact in terms of human and material losses [1]. A wide variety of disasters, natural as well as manmade are faced by human beings, since the beginning of human evolution [2]. A disaster may lead to number expected adjustments: immediate displacement from place of living and community, difficulties in temporary shelters, lose of livelihood, uncertainties about future and demands of rebuilding of life [3]. However the major impact of disaster could be mitigated by proper household emergency preparedness $[4,5]$. The resilience is a core component of disaster preparedness as "the capacity of individuals and systems to cope and maintain positive functioning in the face of significant adversity or risk" [6]. Emergency preparedness involves knowing the risks particular to a community, developing an emergency plan, and having an emergency kit in the home containing food, water, and medical supplies to shelter in place for $72 \mathrm{~h}[7,8]$.

\section{Need of Disaster Kit}

The human and economic loss resulting from disasters have made the community and nations to think on strategies for mitigating the risk and vulnerability associated with it. The survival after a disaster should be thought and planned in advance. The planning involves preparation in terms of food, water and other supplies in sufficient quantity for a minimum of three days or until the rescue workers arrival. The arrival of rescuers depends on the extend of distraction occurred. Furthermore a proper planning helps the survivors to continue their life in the midst of breakdown of basic amenities like electricity, communication system, cooking gas, water, waste disposal and treatment. The exit time available during the evacuation plan on sudden warning sign of disaster will be only few seconds which alarms the necessity of an emergency disaster supply kit [9]. A paradigm shift towards community based preparedness in recent years is preparation of emergency disaster preparedness kit. A disaster supplies kit includes all the basic items for the members of the family in the event of catastrophe. Moreover the scientific technological advancement or the nature itself will give warning to disastrous events which can happen at any time either in home, in vehicle or at office which warrants each one of us to be ready anytime with basic supplies to sustain our life [10-12].

\section{Disaster Preparedness Kit [10]}

\section{Kit location}

The exact location of an individual at the time of a disaster varies. It can be home, work place or being travelling in car. a) At home: Disaster preparedness kit can be kept at a place which can be accessible and familiar to everyone in the family. b) Workplace: Disaster preparedness kit should have to be kept in a container, to facilitate "take and go" in case immediate warning for evacuation comes. Make sure you have comfortable walking or running shoes in your disaster preparedness kit, if evacuation requires walking of long distances. c) At car: If you are stranded in a car, keep a kit of disaster supplies in your car. The kit in your car must contain food, water, first aid supplies, jumper cables, flares and seasonal supplies according to weather (Table 1).

\section{Contents of kit}

1. Water: a) Quantity of water; A normally active person needs about three quarters of a gallon of fluid daily, from water and other beverages. Hence forth storing one gallon of water per person for three days would be adequate. However the following points has to be taken into consideration while estimating the amount of water to be kept in disaster preparedness kit: Personal needs vary, depending on physical condition, gender, age group, activity, dietary pattern and climatic condition. Children, sick individuals, nursing mothers, need more amount of water, hot weather condition can double the amount of water requirement. Furthermore a medical emergency 
Table 1: Basic disaster supply kit [10].

\begin{tabular}{|c|c|}
\hline Serial Number & Item \\
\hline 1. & Fater \\
\hline 2. & Battery-powered or hand crank radio \\
\hline 3. & Flashlight and extra batteries \\
\hline 4. & First aid kit \\
\hline 5. & Dust mask to to signal for help \\
\hline 6. & Moist towelettes, garbage bags and plastic ties \\
\hline 7. & Wrench or pliers \\
\hline 8. & Manual can opener for food \\
\hline 9. & Local maps \\
\hline 10. & Cell phone with chargers, inverter or solar charger \\
\hline 11. & \\
\hline 12. & \\
\hline
\end{tabular}

might demands additional quantity of water b) Storage of water: i) The most reliable supply of water to store is bottled drinking water from market. The bottle should be unopened till the time of use and ensure the expiry of water bottle ii) The water can be stored in unbreakable food grade water storage containers from supply stores which should be cleaned with dish wash soap solution, and water iii) Storage containers such as two litre plastic soft drink bottles can be utilized but preferred to avoid containers that had milk or fruit juice in them. The following steps are helpful while storing water in plastic bottles: 1 . Thoroughly clean the bottles with soap solution and rinse out soap completely from it. Sanitize the bottles with one tea spoon of non-scented liquid domestic chlorine bleach to quarter litre of water. Swish the solution thoroughly in the bottle to touch all the surfaces .After sanitization, rinses out the sanitizing solution with clean water. 2. Fill the bottle with commercially treated water, if water is treated no need for adding anything to cleanse the water. If well water or from other safe water sources which are not properly treated, add two drops of non-scented liquid house hold chlorine bleach to the water. 3. Tighten the container with original cap, while capping be careful enough not to contaminate the cap by touching inside of it with soiled finger or any other articles. Place the filling date on outside the container, so that you will come to know when you filled, store it in a cool, dark place. Replace the water at every six month interval if not using commercially bottled water.

2. Food: a) Choose salt free cookies, whole grain cereals, and canned foods with high liquid content and avoid foods that will make you thirsty b) keep ready canned foods, dry fruits, high calorie yielding food stuffs like nuts, peanut butter, one box of twelve or more high-energy bars or snacks. One can of meat or protein such as spam or underwood chicken spread, other staple food of your own choice, which does not require refrigeration, cooking, water or special preparation c) Keep a manual can opener, if you prefer canned foods. d) Make sure all edibles are marked boldly with an expiry date. e) special diet is required for babies such as baby food formulas as per age available in the market [13].f) For old age persons, with constipation problem or on a semisolid or liquid diet arrange canned semisolid or liquid diet $[13,14]$. g) a minimum of three days supply of non perishable food should have to be included in the disaster preparedness kit and has to be changed on time by time, as per expiry date.

3. Other items: The disaster kit should contain the following other items which are pertinent for the survival apart from the basic supply of life-water and food. The comprehensive list includes a) Portable, battery powered radio and extra batteries. b) Flashlight with extra batteries. c) Whistle to signal for help, metal one is better than plastic whistle. d) First aid kit which should have plasters in a variety of different sizes and shapes- small, medium, large sterile gauze dressings, at least two sterile eye dressings, triangular bandages, crepe rolled bandages, safety pins, disposable sterile gloves, tweezers, scissors, alcohol free cleansing wipes, sticky tape, thermometer preferably digital, skin rash cream such as hydrocortisone, cream or spray to relieve insect bites and stings, antiseptic cream, pain killers such as paracetamol, aspirin, ibuprofen, cough medicines, anti histamine tablets, distilled water for cleaning wounds, eye wash and eye bath [10]. e) Dust mask to help filter contaminated air and plastic sheeting and duct tape to shelter in place f) Moist toilettes, garbage bags and plastic ties for personal sanitation g) Cell phone with power bank, extra cord for smart phones h) Local map-hard copy of your residence area i) Mosquito repellents j) Lantern k) Address book with important phone numbers l) Photocopies of identification and credit cards with number $\mathrm{m}$ ) Copies of important papers including wills and policies $\mathrm{n}$ ) Clothing including long pants and long sleeve shirt o) Personal hygiene items tooth paste and ONE tooth brush per family member p) Utensils. q) Paper and pencils r) Knife s) Extra cash t) Matches in a water proof container u) Special need items such as prescription of medications, eye glasses, contact lens and its solution, hearing aid with batteries'v) Items for infants such as diapers, feeding bottle and pacifiers w) Changes of clothing for each family member [15-18].

\section{Maintenance of kit}

The maintenance of kit is equally important as preparation considering the safety of stored items. The measures which can be initiated are: a) Keep canned food in a cool, dry place b) Store boxed food in tightly closed plastic or metal containers to protect from pests and to extend its shelf life. c) Throw out any canned good that becomes swollen, dented or corroded d) Use foods before they go bad and replace them with fresh supplies e) Place new items at the back of the storage area and older ones in the front. f) Change stored food and water supplies every six months. Be sure to write the date you store it on all containers g) Re-think your needs every year and update your kit as your family's needs change. h) Keep items in airtight plastic bags and put your entire disaster supplies kit in one or two easy-tocarry containers, such as an unused trashcan, camping backpack or duffel bag [10].

\section{Discussion}

The national and international regulatory bodies in the developing and developed countries have clear-cut policy guidelines for household emergency preparedness but the depth at which the knowledge and practice regarding the same has been rooted in the community is questionable. Indeed the studies carried out in US reveal that only $30-40 \%$ of Americans have emergency supplies or family communication plans [19] while seventy-five percent of respondents from another study were categorized as being 'minimally prepared' or 'not prepared' because of their lack of emergency supplies [20]. 
The decreased rate of adherence to family disaster preparedness by preparing and maintaining a disaster kit can be multi factorial a) Lack of knowledge regarding what to prepare-The public may be unaware of the concept of disaster kit, items in disaster kit and maintenance of disaster kit. Much of the information related to disaster preparedness are internet based and it will not reach the people who do not have internet access-Multiple channels of communication must be utilized to diffuse the information on disaster kit to the public [21-28]. b) Majority of people have an unrealistic sense of optimism and feel no danger or threats will arise and feel subjectively prepared for disaster but are objectively unprepared [26,29]. c) People feel that it is quiet inconvenient to maintain the disaster kit considering the space, money and time consumed by the same $[23,25,26]$. d) lack of efficacy expectations (i.e. the belief that preparedness measures cannot prevent a disaster. Research need to be conducted regarding the effectiveness of disaster kit in improving self sufficiency of individuals and disaster related resilience. The association between being prepared for disaster and surviving the disaster without outside assistance should be clearly ruled out by using a household emergency preparedness instrument which can further strengthen the effectiveness of disaster preparedness kit. An effective collaboration between the government agencies and community are essential for disaster preparedness since it is a dynamic, multifaceted, large-scale public health concern. Community education on disaster preparedness is the only effective tool to address the gap existing between the disaster management authorities and public.

\section{Conclusion}

The policies formulated by global organizations on disaster preparedness have highlighted the roles and responsibilities to be carried out by the individual and community in mitigating the risk and vulnerabilities associated with disasters. Moreover empowering the local level preparedness from the incipient units in the community i.e. each individual household is an essential part of effective response and recovery. Furthermore an effective citizen and community preparedness warrants public awareness and education programs to ensure citizens will take appropriate advance actions to reduce their vulnerability especially during the initial days (72hrs) after disaster impact. The Disaster preparedness kit is an indispensable part of preparedness and it should start with a gold standard set of essential supplies. This gold standard should be based on the common conditions that any natural or manmade disaster would likely present and equip each household to face the common conditions. In particular, the common conditions include living without power, limitations on drinking water, and being unable to leave the home to acquire additional supplies for a few a days. The goal of a gold standard is to provide everyone with proven essentials so individuals and households are empowered to further customize their disaster supply kits to best serve their unique needs [30]. For people to take action, they must recognize the hazard, believe it to be avoidable, and believe that there is an advantage in taking preventative actions [3133].

\section{References}

1. Government of India. National Disaster Management Division. Series 2. Disaster Management Programme. New Delhi: Ministry of Home Affairs; 2002.
2. Park K. Text book of Preventive and Social Medicine. Jabalpur: M/s. Banarsidas Bhanot; 2011; 600-605.

3. Disaster preparedness. Times Foundation India Times. 2006.

4. Falkiner L. Impact analysis of the Canadian Red Cross Expect the Unexpected Program. 2003.

5. Keim ME. Building human resilience: The role of public health preparedness and response as an adaptation to climate change. American Journal of Preventive Medicine. 2008; 35: 508-516.

6. Martin, K. A shared responsibility: The need for an inclusive approach to emergency planning for people with disabilities. Vancouver BC: BC Coalition of People with Disabilities. 2009.

7. Canadian Red Cross. Emergency preparedness. 2010.

8. Public Safety and Emergency Preparedness Canada. Your emergency preparedness guide. 72 hours. Is your family prepared? 2006.

9. Rao DP. Disaster Management. 2006.

10. Are you ready? Assemble a disaster supplies kit. Federal emergency management authority.

11. Government of India. Draft study on community involvement in disaster management.

12. Kandaswamy M. Community health nurse in disaster nursing. The Nursing Journal of India. 2007; 98: 227-229.

13. Blessman J, Skupski J, Jamil H. Barriers to at home preparedness in public health emergencies. Journal of occupational Environment. 2007; 49: 318326.

14. Sanders S, Bowie SL, Bowie YD. Lessons learned on forced relocation of older adults: the impact of Hurricane Andrew on health, mental health, and social support of public housing residents. Journal of Gerontological Social Work. 2003; 40: 23-25.

15. Elizabeth W, Margaret I, Patricia T, Jeffry G. Emergency preparedness curriculum in nursing schools in the United States. Nursing educational perspectives. 2005; 32: 334- 339.

16. Philips BD, Metz WE, Nieves LA. Disaster threat: preparedness and potential responses of lowest income quartile. Environmental Hazard. 2005; 6: 123133.

17. Burke RV, Ferrer RR, Goodhue CJ. Disaster preparedness among medical students: a survey assessment. American Journal of Disaster Medicine. 2010; 5: 275-284.

18. Catherine JG, Rita VB, Santiago C. Disaster olympics: A unique nursing emergency preparedness exercise. Journal of Trauma Nursing. 2010; 17: 5-11.

19. Page L, Rubin J, Amlot R, Simpson J, Wessely S. Are Londoners prepared for an emergency? A longitudinal study following the London bombings. Biosecurity \& Bioterrorism. 2008; 6: 309-319.

20. Blessman J, Skupski J, Jamil M, Jamil H, Bassett D, Wabeke R, et al. Barriers to at-home-preparedness in public health employees: Implications for disaster preparedness training. Journal of Occupational and Environmental Medicine. 2009; 49: 318-326

21. Al-Rousan TM, Rubenstein LM, Wallace RB. Preparedness for natural disasters among older US adults: a nationwide survey. Am J Public Health. 2014; 104: 506-511.

22. Baker L, Cormier L. Disaster preparedness and families of children with special needs: a geographic comparison. J Community Health. 2013; 38: 106-112.

23. Murphy S, Cody M, Frank L, Glik D, Ang A. Predictors of emergency preparedness and compliance. Disaster Med Public Health Prep. 2009; 3: $51-59$.

24. Chesser A, Ablah E, Hawley S, et al. Preparedness needs assessment in a rural state: themes derived from public focus groups. Biosecur Bioterror. 2006; 4: 376-383. 
25. Eisenman D, Glik D, Maranon R, Gonzales L, Asch S. Developing a disaster preparedness campaign targeting lowincome Latino immigrants: focus group results for Project PREP. J Health Care Poor Underserved. 2009; 20: 330345.

26. Perman J, Shoaf K, Kourouyan A, Kelley M. Disaster kit contents: a comparison of published guidelines for household preparedness supplies. Int J Mass Emerg Disasters. 2011; 29: 1-25.

27. Tuohy R, Stephens C, Johnston D. Qualitative research can improve understandings about disaster preparedness for independent older adults in the community. Disaster Prev Manag. 2014; 23: 296-308.

28. Hilfinger-Messias D, Lacy E. Katrina related health concerns of Latino survivors and evacuees. J Health Care Poor Underserved. 2007; 18: 443 463

29. Ablah E, Konda K, Kelley C. Factors predicting individual emergency preparedness: a multi-state analysis of 2006 BRFSS data. Biosecur Bioterror. 2009; 7: 317-330.
30. Kirkpatrick, Heagele. AJPH Letters and Responses. 2016; 106.

31. Diekman ST, Kearney SP, O'Neil ME, Mack KA. Qualitative study on homeowners' emergency preparedness: Experiences, perceptions and practices. Prehospital and Disaster Medicine. 2007; 22: 494-501.

32. Damon SA, Naylor R, Therriault S. Public communication in unplanned biomass burning events. Inhalation Toxicology. 2010; 22: 113-116.

33. Swabir SF, Ansuya, Malathi GN. A Pre experimental study to assess effectiveness of a video awareness programme on disaster preparedness and preparation of families disaster preparedness kit $f$ or urban adults of udupi district south India. International Journal of current Research. 2014; 6: 7132-7136.
J Fam Med - Volume 4 Issue 4 - 2017

ISSN : 2380-0658 | www.austinpublishinggroup.com

Varghese et al. (C) All rights are reserved
Citation: Varghese A, Swabir SF and George G. Disaster Preparedness Kit: An Insight into the Emergency Tool. J Fam Med. 2017; 4(4): 1120 